\title{
Pigmentation of Cultured Black Tiger Prawn by Feeding with a Spirulina-Supplemented Diet
}

\author{
Wen-Liang Liao, ${ }^{* 1,2}$ Shah Amran Nur-E-Borhan, ${ }^{* 1}$ Shigeru Okada, ${ }^{* 1}$ \\ Takashi Matsui, ${ }^{* 1}$ and Katsumi Yamaguchi*1
}

(Received August 23, 1992)

\begin{abstract}
Black tiger prawn Penaeus monodon were fed with diets containing different carotenoid sources: $\beta$-carotene, Spirulina, Phaffia, and krill oil. A marked increase of carotenoid content in the carapace was observed when fed with Spirulina-supplemented diets. The best effect of Spirulina was obtained at $3 \%$ in diets. The analysis of carapace carotenoids in the Spirulina-fed prawns suggests that zeaxanthin, one of major carotenoids in Spirulina, has been rapidly converted to astaxanthin. In view of these findings, we propose that a practical strategy for pigmentation of cultured $P$. monodon is to feed it with a diet containing Spirulina at $3 \%$ for 1 month before harvest.
\end{abstract}

The black tiger prawn Penaeus monodon is cultivated widely in South East Asia, and production has been increasing year by year. The greater part of the product is consumed in Japan, but the external color of cultured prawns is generally pale. The color affects the price in the market, well-pigmented prawns being more acceptable because the desirable red coloration can be expected when cooked.

Carotenoids and carotenoproteins are responsible for the color of crustaceans. ${ }^{12}$ The distribution and metabolic pathways of carotenoids in Crustacea have been reviewed by Goodwin, ${ }^{2)}$ Davis, ${ }^{3)}$ and Matsuno and Hirao. ${ }^{4}$ Tanaka et al. $^{5)}$ investigated the metabolism of dietary carotenoids in the prawn $P$. japonicus and suggested the presence of the following two oxidative pathways:

$\beta$-carotene $\longrightarrow$ isocryptoxanthin $\longrightarrow$ echinenone $\longrightarrow$ canthaxanthin $\longrightarrow$ phoenicoxanthin $\longrightarrow$ astaxanthin: zeaxanthin $\longrightarrow$ 4-ketozeaxanthin $\longrightarrow$ astaxanthin.

They also reported that the prawn could directly deposit dietary astaxanthin in their tissues. Yamada et $a l^{\left({ }^{3}\right)}$ and Chen and Jeng ${ }^{7)}$ carried out a pigmentation test on $P$. japonicus by various carotenoid sources and levels and feeding regimes.

Recently, astaxanthin was shown to be a predominant carotenoid associated with the body color of the black tiger prawn $P$. monodon. ${ }^{3}$;
However, no pigmentation attempt has been made so far for $P$. monodon.

The purpose of this study was to find a suitable pigmenter and to establish a practical strategy of pigmentation for cultured $P$. monodon through feeding experiments.

\section{Materials and Methods}

\section{Composition and Preparation of Diets}

Four kinds of carotenoid sources, i.e. $\beta$ carotene, Spirulina, Phaffia, and krill oil were used. $\beta$-Carotene was purchased from Sigma Chem. Co. Spirulina was a spray-dried product of mass-cultivated blue-green alga $S$. maxima from Japan Spirulina Co., Ltd. The content and composition of carotenoids were analyzed by the method of Miki et al. ${ }^{93}$ with slight modifications, and were found to be $346 \mathrm{mg} / 100 \mathrm{~g}$ excluding carotenoid glycosides and $52 \% \beta$-carotene, $10 \%$ echinenone, $6 \% \beta$-cryptoxanthin, $5 \% 3^{\prime}-$ hydroxyechinenone, $21 \%$ zeaxanthin including cis-zeaxanthins, and $7 \%$ decomposed and unidentified carotenoids. Phaffia and krill oil were supplied by Nippon Suisan Co. The former was a dried preparation of the yeast Phaffia rhodozyma, of which carotenoid content and composition were $84 \mathrm{mg} / 100 \mathrm{~g}$ and $4 \%$ astaxanthin diester, $33 \%$ astaxanthin monoester, $45 \%$ astaxanthin, and $18 \%$ unknown. The

*1 Laboratory of Marine Biochemistry, Faculty of Agriculture, The University of Tokyo, Yayoi, Bunkyo,

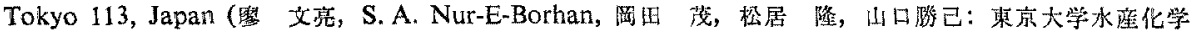
研究室).

*2 Present address: Institute of Fisheries Sciences, National Taiwan University, Taipei, Taiwan, Republic of China (国立台海大学潐業科学研究所). 
Table 1. Composition of test diets for feeding experiments $(\mathrm{g} / 100 \mathrm{~g})$

\begin{tabular}{|c|c|c|c|c|c|c|c|}
\hline \multirow{2}{*}{ Ingredients } & \multicolumn{7}{|c|}{ Diet no. } \\
\hline & 1 & 2 & 3 & 4 & 5 & 6 & 7 \\
\hline White fish meal & 50 & 50 & 50 & 50 & 50 & 50 & 50 \\
\hline Wheat fiour & 10 & 10 & 10 & 10 & 10 & 10 & 10 \\
\hline Corn gluten & 5 & 5 & 5 & 5 & 5 & 5 & 5 \\
\hline Beef liver meal & 3 & 3 & 3 & 3 & 3 & 3 & 3 \\
\hline Mineral mixture*i & 5 & 5 & 5 & 5 & 5 & 5 & 5 \\
\hline $\mathrm{Oil}^{* 2}$ & 2 & 2 & 2 & 2 & 2 & 2 & 2 \\
\hline Vitamin mixture ${ }^{* 3}$ & 1.5 & 1.5 & 1.5 & 1.5 & 1.5 & 1.5 & 1.5 \\
\hline Vitamin $E^{* 4}$ & 0.1 & 0.1 & 0.1 & 0.1 & 0.1 & 0.1 & 0.1 \\
\hline Choline chloride & 0.5 & 0.5 & 0.5 & 0.5 & 0.5 & 0.5 & 0.5 \\
\hline Cholesterol & 0.5 & 0.5 & 0.5 & 0.5 & 0.5 & 0.5 & 0.5 \\
\hline Dextrin & 22.4 & 22.39 & 19.4 & 10.4 & 11.4 & 21.4 & 17.4 \\
\hline$\beta$-Carotene & - & 0.01 & - & - & - & - & - \\
\hline Spirulina & - & - & 3 & - & - & 1 & 5 \\
\hline Phaffia & - & - & - & 12 & - & - & - \\
\hline Krill oil & - & - & - & - & 11 & - & - \\
\hline $\begin{array}{ll}* 1 & \mathrm{Ca}\left(\mathrm{H}_{2} \mathrm{PO}_{4}\right)_{2} \cdot \mathrm{H}_{2} \mathrm{O}: \mathrm{C} \\
* 2 & \text { Pollack liver oil: Soy } \\
* & \text { A preparation of Nip } \\
* & \text { The DL- } \alpha \text {-tocopheryl }\end{array}$ & $\begin{array}{l}1 . \\
\text { in }=1: \\
\text { e K.K. }\end{array}$ & & & & & & \\
\hline
\end{tabular}

latter contained almost exclusively astaxanthin diester at a concentration of $93 \mathrm{mg} / 100 \mathrm{~g}$ in terms of astaxanthin. ${ }^{10)}$ The composition of test diets are presented in Table 1.

Two feeding experiments were carried out. In experiment $I$, the effects of the four pigmenters were examined, Diet 1 was the control diet (carotenoid-deficient). Diets 2 to 5 were supplemented with one of the four pigmenters, and total carotenoid level was adjusted to around $10 \mathrm{mg} / 100 \mathrm{~g}$ with dextrin. As will be described in the Results section, Spirulina was found to be most effective, so in experiment II the minimum dose of Spirulina required for desirable pigmentation was checked using diets $1,3,6$, and 7 . Diet 1 again was the control, and diets 6,3 , and 7 contained Spirulina at 1, 3, and 5\%, respectively.

The ingredients were mixed with 30 to $35 \%$ (v/w) water and kneaded. The dough so obtained was extruded into pellets using a meat mincer with holes of $1.9 \mathrm{~mm}$ diameter, and was then dried in a freeze vacuum dryer at $-40^{\circ} \mathrm{C}$ overnight until the moisture content was reduced to about $10 \%$. They were stored in a freezer at $-25^{\circ} \mathrm{C}$ until use.

\section{Feeding Experiments}

Live juvenile prawns $P$. monodon were obtained from Taiwan. The feeding experiments were carried out at the Fisheries Laboratory, Faculty of Agriculture, The University of Tokyo, Shizu- oka, Japan. In experiment I, prawns were fed with the control diet for 10 days and then randomly divided into 5 groups, each with 45 individuals (average weight $1.1 \mathrm{~g}$ ), and placed in outdoor concrete pools $(2 \times 1 \mathrm{~m}$; depth of water, $42 \mathrm{~cm})$. In experiment II, prawns were fed with shortneck clam meat and the control diet for 31 days before starting the experiment. The animals (average weight $0.61 \mathrm{~g}$ ) were divided into 4 groups, each with 14 individuals, and reared in plastic containers $(40 \times 30 \mathrm{~cm}$; depth of water $20 \mathrm{~cm}$ ).

In both experiments sea water was supplied at a flow rate of 4 to $6 \mathrm{l} / \mathrm{min}$. Salinity was maintained at 29 to $30 \%$ with freshwater and constant aeration. Water temperature varied between 24 and $30^{\circ} \mathrm{C}$ during the experiments. Diets were given twice a day at $8: 00$ and $17: 30$. The feeding levels were 7 to $8 \%$. Faeces, sloughs, and uneaten diets were cleaned everyday. Feed intake was calculated by deducting the amount of diet uneaten from that given.

On the basis of preliminary tests, we set the feeding duration to about 1 month. The adequacy of this period was confirmed for $P$. japonicus by Chen and Jeng ${ }^{7}$ who reported that there was no difference in pigmentation among prawns fed with the pigmented diets for 1, 2, or 3 months. Both experiments I and II were carried out for 28 days and the weight of each prawn was measured on day 14 and 28 . The 
Table 2. Results of the feeding trial in experiment I

\begin{tabular}{|c|c|c|c|c|c|c|c|}
\hline \multirow{2}{*}{$\begin{array}{l}\text { Diet } \\
\text { no. }\end{array}$} & \multicolumn{3}{|c|}{ Body weight $(\mathrm{g})^{* 1}$} & \multicolumn{2}{|c|}{ Percent gain } & \multicolumn{2}{|c|}{ Feed efficiency*2 } \\
\hline & Initial & 14 days & 28 days & 14 days & 28 days & 14 days & 28 days \\
\hline 1 & $1.13 \pm 0.26$ & $1.99 \pm 0.67$ & $3.99 \pm 1.34$ & 76 & 253 & 0.59 & 0.70 \\
\hline 2 & $1.14 \pm 0.24$ & $2.04 \pm 0.54$ & $4.19 \pm 1.00$ & 79 & 268 & 0.62 & 0.75 \\
\hline 3 & $1.13 \pm 0.25$ & $1.91 \pm 0.65$ & $4.04 \pm 1.13$ & 69 & 258 & 0.54 & 0.78 \\
\hline 4 & $1.14 \pm 0.21$ & $1.72 \pm 0.42$ & $3.14 \pm 0.73$ & 51 & 175 & 0.40 & 0.56 \\
\hline 5 & $1.14 \pm 0.21$ & $2.13 \pm 0.59$ & $4.48 \pm 1.11$ & 87 & 267 & 0.68 & 0.68 \\
\hline
\end{tabular}

*1 Mean \pm standard deviation (initial number $=45$ ).

*2 g gain/g feed.

prawns were harvested on day 28 and stored at $-20^{\circ} \mathrm{C}$ until being analyzed.

\section{Carotenoid Analysis}

The carapace of individual prawns was removed, cut into small pieces, and ground in a mortar with anhydrous sodium sulfate. Carotenoids were extracted repeatedly with acetone until they could not be detected by color. The extracts were combined and concentrated under reduced pressure. The concentrate was transferred to a separating funnel and the carotenoids were taken up in diethyl ether. The ethereal layer was washed with water, dried on anhydrous sodium sulfate, and concentrated to dryness under reduced pressure. The residue was dissolved in benzene to make a volume. Total carotenoid was determined at $480 \mathrm{~nm}$ by the method of $\mathrm{McBeth}^{11)}$ with a Hitachi 330 spectrophotometer. The carotenoids were subjected to silica gel column chromatography. $\beta$-Carotene was eluted with $n$-hexane, followed by the remaining carotenoids with methanol. The carotenoid content of both fractions was determined by the same methods as for total carotenoid. The carotenoids, except $\beta$-carotene, were hydrolyzed with lipase according to the method of Matsuno et al.,2) and separated by HPLC on a column of Superiorex-ODS $(150 \times 4.6 \mathrm{~mm})$ with a mobile phase of methanol/ ethylacetate/water $(54: 15: 10)$ at a flow rate of $0.7 \mathrm{ml} / \mathrm{min}$. Individual carotenoids were identified by spectroscopic analysis with a Shimadzu SPD-M6A photodiode array and by co-HPLC with authentic standards. The relative percentages were determined from peak areas on HPLC.

\section{Measured Parameters and Data Treatment}

Percent gain and feed efficiency were calculated according to Deshimaru. ${ }^{13}$ The carotenoid contents were analyzed by Student's " $t$ "' test at a significant level of $5 \%$.
Table 3. Content of carotenoids in the carapace on day 28 in experiment I $(\mathrm{mg} / 100 \mathrm{~g})^{* * 1}$

\begin{tabular}{clc}
\hline Diet no. & Pigmenter & Content \\
\hline 1 & None & $8.08 \pm 1.27$ \\
2 & B-Carotene & $9.15 \pm 0.89$ \\
3 & Spirulina & $12.02 \pm 1.95^{* 2}$ \\
4 & Phaffia & $8.50 \pm 1.30$ \\
5 & Krill oil & $8.46 \pm 0.62$ \\
\hline *1 & Mean \pm standard deviation $(\mathrm{n}=4)$. \\
*2 & The value is significantly different from that of diet 1 at the \\
& $5 \%$ level.
\end{tabular}

\section{Results}

Table 2 shows the results of the feeding trial in experiment I. The prawns receiving Phaffia (diet 4) showed retarded growth, though the reason is not apparent. In the other diet groups the animals grew well. At the final stage of the feeding trial the body color of prawns in the control group remained light, whereas that of prawns receiving Spirulina (diet 3) was very dark. The animals receiving diets 2,4 , and 5 showed intermediate coloring between the control and Spirulina groups. The body color turned to red on boiling for $15 \mathrm{~min}$ at $100^{\circ} \mathrm{C}$ and the same trend in the deepness of body color was observed as before boiling. The content of carotenoids in the carapace was determined individually and is shown in Table 3. Evidently, the figures in Table 3 supported the above observation; carotenoids of the prawns receiving Spirulina increased conspicuously. Thus Spirulina proved to be most effective for pigmentation of cultured $P$. monodon among the pigmenters examined.

In experiment II, the effects of diets formulated at different levels of Spirulina on the pigmentation were examined. Table 4 shows the results of the feeding trial. The prawns fed with Spirulina showed less growth compared to that of the control group for 2 weeks, probably due to unfamiliarity with the Spirulina-containing diet. 
Table 4. Results of the feeding trial in experiment II

\begin{tabular}{|c|c|c|c|c|c|c|c|c|}
\hline \multirow{2}{*}{$\begin{array}{l}\text { Diet } \\
\text { no. }\end{array}$} & \multirow{2}{*}{$\begin{array}{c}\text { Level of } \\
\text { Spirulina } \\
\text { supplement }(\%)\end{array}$} & \multicolumn{3}{|c|}{ Body weight $(\mathrm{g})^{* 1}$} & \multicolumn{2}{|c|}{ Percent gain } & \multicolumn{2}{|c|}{ Feed efficiency*2 } \\
\hline & & Initial & 14 days & 28 days & 14 days & 28 days & 14 days & 28 days \\
\hline 1 & 0 & $0.61 \pm 0.29$ & $1.04 \pm 0.53$ & $1.43 \pm 0.6$ & 70 & 134 & 0.49 & 0.36 \\
\hline 6 & 1 & $0.61 \pm 0.29$ & $0.96 \pm 0.45$ & $1.62 \pm 0.3$ & 57 & 166 & 0.41 & 0.41 \\
\hline 3 & 3 & $0.61 \pm 0.27$ & $0.94 \pm 0.43$ & $1.50 \pm 0.4$ & 54 & 146 & 0.38 & 0.39 \\
\hline 7 & 5 & $0.60 \pm 0.24$ & $0.89 \pm 0.41$ & 1. $32 \pm 0.6$ & 48 & 120 & 0.36 & 0.32 \\
\hline
\end{tabular}

* Mean 1 standard deviation (initial number $=14$ ).

*2 g gain/g feed.

Table 5. Content of carotenoids in the carapace on day 28 in experiment II $(\mathrm{mg} / 100 \mathrm{~g})^{*}$

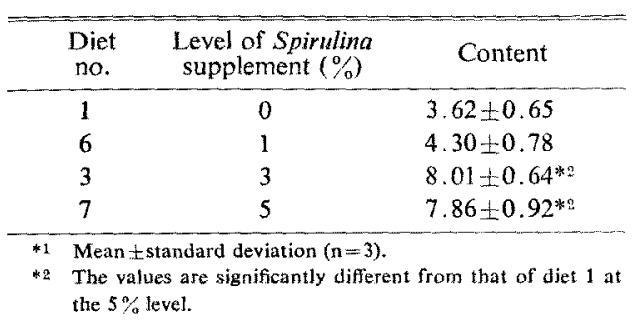

Table 6. Composition of carotenoids in the carapace of prawns fed the $3 \%$ Spirulina-supplemented diet on day 28 $(\%)$

\begin{tabular}{lc}
\hline Carotenoid & Composition \\
\hline$\beta$-Carotene & 12.4 \\
Phoenicoxanthin & 0.5 \\
4-Ketozeaxanthin & 0.4 \\
Astaxanthin & 68.7 \\
Unknown & 18.0 \\
\hline
\end{tabular}

This tendency was also found in diet 3 of experiment I (Table 2). Thereafter, however, the prawns fed with diets containing 1 and $3 \%$ Spirulina grew well, body weight surpassing that of the control group on day 28 . In contrast, the growth of prawns receiving $5 \%$ Spirulina remained retarded. This may be due to the high content of Spirulina, because the alga was found to have an adverse effect on the growth of some cultured fish when fed too much of it, ${ }^{14}$.

The body color of the prawns at the final stage of the experiment was deeper with the increase of the level of Spirulina from 1 to $3 \%$. However, little difference was observed in the prawns fed with diets supplemented with 3 and $5 \%$ Spirulina. This observation was evidenced by the analysis of carotenoid content in the carapace as shown in Table 5. The contents gradually increased in the prawns fed with 1 and $3 \%$ Spirulina, when compared to the control group.
A slightly lower value was obtained in the prawns fed with $5 \%$ Spirulina, suggesting a $3 \%$ supplement in the diet to be the saturation level as far as carotenoid capacity in the carapace is concerned.

The composition of carotenoids deposited in the carapace of prawns fed with the $3 \%$ Spirulinasupplemented diet in experiment $I$ was analyzed to follow the bioconversion of dietary carotenoids. Table 6 shows the results. Astaxanthin, unknown, and $\beta$-carotene accounted for 69,18 , and $12 \%$ of the whole carotenoids, respectively. Unknown carotenoids consisted of decomposed products and highly polar ones. Only phoenicoxanthin was present in the oxidative pathway from $\beta$-carotene to astaxanthin. On the other hand, no zeaxanthin and only a trace amount of 4-ketozeaxanthin were found, both of which are members in the other oxidative pathway to astaxanthin.

\section{Discussion}

We estimated astaxanthin to be most effective as a pigmenter, because it has been reported that $P$. japonicus can directly deposit dietary astaxanthin in the tissues. ${ }^{5,6}$ However, feeding of Phaffia and krill oil, both of which contained astaxanthin esters as predominant carotenoid, to $\boldsymbol{P}$. monodon proved less effective. The reason is not known, but there is a possibility that the incorporation of esterified carotenoids by crustaceans is more delayed than that of free carotenoids.

Bioconversion of $\beta$-carotene to astaxanthin requires many oxidative steps, ${ }^{5)}$ suggesting $\beta$ carotene to be less effective as a pigmenter. Actually, the low rate of incorporation of this carotenoid was found in the present feeding experiment and similar results were reported for $P$, japonicus. $\left.{ }^{6}, 7\right)$ Spirulina has $\beta$-carotene and zeaxanthin as major carotenoids. Thus, the effectiveness of Spirulina as a pigmenter of $P$. 
monodon is attributable to zeaxanthin, that can be converted into astaxanthin via 4-ketozeaxanthin. ${ }^{5)}$ Analysis of carapace carotenoids of prawns which received the Spirulina-supplemented diet revealed that no zeaxanthin and only a small amount of 4-ketozeaxanthin were found (Table 6). This finding suggests that dietary zeaxanthin has rapidly been metabolized to astaxanthin in $\boldsymbol{P}$. monodon. That may be the reason why Spirulina worked effectively in pigmentation.

In experiment II, we found that there was essentially no difference in the pigmentation of prawns by feeding with 3 or $5 \%$ Spirulinasupplemented diet, and that the growth in the latter group was somewhat retarded (Tables 4 and 5). In this context, Watanabe et al.14) observed that over-supplementation of dietary Spirulina for cultured striped jack caused retardation of growth. Economically, the smaller the amount of Spirulina, the better.

In conclusion, a practical strategy for pigmentation of cultured $P$. monodon is to feed it with a diet containing Spirulina at $3 \%$ for 1 month before harvest.

\section{Acknowledgments}

This research was supported by a grant from the Food Science Institute Foundation, Japan (Ryoshoku Kenkyukai). Special thanks are due to Prof. T. Watanabe and the staff of the Department of Aquatic Bioscience, Tokyo University of Fisheries, for the preparation of test diets, and to Dr. H. Sato and the staff of the Fisheries Laboratory, Faculty of Agriculture, The University of Tokyo as well as to Mr. S. Taketsugu for the feeding experiments. Thanks are also due to Dr. D.-L. Lee of Tungkang Marine Laboratory, Taiwan for providing live $P$. monodon.

\section{References}

1) G. Britton, G. M. Armitt, S. Y. M. Lau, A. K. Patel, and C. C. Shone: Carotenoproteins, in "Carotenoid Chemistry \& Biochemistry" (ed. by G. Britton and T. W. Goodwin), Pergamon Press, Oxford, 1981, pp. 237-251.

2) T. W. Goodwin: The Biochemistry of the Carotenoids, 2 nd ed., Chapman and Hall, London, 1984, pp. 64-96.

3) B. H. Davis: Carotenoid metabolism in animals: $A$ biochemist's view. Pure Appl. Chem, 57, 679-684 (1985).

4) T. Matsuno and S. Hirao: Marine Carotenoids, in "Marine Biogenic Lipids, Fats, and Oils" (ed. by R. G. Ackman), Vol. I, CRC Press, Florida, 1989, pp. 251-388.

5) Y. Tanaka, H. Matsuguchi, T. Katayama, K. L. Simpson, and $C$. O. Chichester: The biosynthesis of astaxanthinXYIII. The metabolism of the carotenoids in the prawn Penaeus japonicus Bate. Nippon Suisan Gakkaishi, 42, 197 202 (1976).

6) S. Yamada, X. Tanaka, M. Sameshima, and Y. Ito: Pigmentation (Penaeus japonicus) with carotenoids. 1. Effect of dietary astaxanthin, $\beta$-carotene and canthaxanthin on pigmentation. Aquaculture, 87, 323-330 (1990).

7) Y.H. Chen and S.-C. Jeng: Pigmentation of kuruma prawn, Penaeus japonicus Bate, by various pigment sources and levels and feeding regines, Aquaculture, 102, 333-346 (1992).

8) B. K. Howell and A. D. Matthews: The carotenoids of wild and blue diseaseaffected farmed tiger shrimp (Penaeus monodon, Fabricus). Comp. Biochem. Phystol, 98 B, 375 379 (1991).

9) W. Miki, K. Yamaguchi, and S. Konosu: Carotenoid composition of Spirulina maxima. Nippon Suisan Gakkaishi, 52, 1225-1227 (1986).

10) K. Yamaguchi, W. Miki, N. Toriu, Y. Kondo, M. Murakami, S. Konosu, M. Satake, and T. Fujita: The composition of carotenoid pigments in the Antarctic krill Euphausia superba. Nippon Suisan Gakkaishi, 49, 1411-1415 (1983).

11) J. W. McBeth: Carotenoid from nudibranchs. Comp. Biochem. Physiol, 41 B, 55-68 (1972).

12) T. Matsuno, M* Ookubo, T. Nishizawa, and I. Shimizu: Carotenoids of sea squirts. I. New marine carotenoids, halocynthiaxanthin and mytiloxanthinone from Halocynthia roretzi. Chem. Pharm. Bull, 32, 4309-4315 (1984).

13) O. Deshimaru: Studies on nutrition and diet for prawn Penqeus japonicus. Mem. Kagoshima Pref. Fish. Expt. Stn. No. 12, 1-118 (1981).

14) T. Watanabe, W.-L. Liao, T. Taketuchi, and H. Yamamoto: Effect of dietary Spirulina supplementation on growth per. formance and flesh lipids of cultured striped jack. J. Tokyo Univ. Fish., 77, 231-239 (1990). 